\title{
Using Multispectral Imaging to Measure Temperature Profiles and Emissivity of Large Thermionic Dispenser Cathodes \\ David F. Simmons, ${ }^{1}$ Clifford M. Fortgang, ${ }^{2}$ and David B. Holtkamp ${ }^{2}$ \\ ${ }^{1}$ Bechtel Nevada-Los Alamos, ${ }^{2}$ Los Alamos National Laboratory
}

\section{Introduction}

Thermionic dispenser cathodes are widely used in modern high-power microwave tubes. Use of these cathodes has led to significant improvement in performance. In recent years these cathodes have been used in electron linear accelerators (LINACs), particularly in induction LINACs, such as the Experimental Test Accelerator at Lawrence Livermore National Laboratory and the Relativistic Test Accelerator at Lawrence Berkeley National Laboratory. For induction LINACs, the thermionic dispenser cathode provides greater reproducibility, longer pulse lengths, and lower emittance beams than does a field emission cathode. ${ }^{[1,2]}$

Los Alamos National Laboratory is fabricating a dual-axis X-ray radiography machine called dual-axis radiograph hydrodynamic test (DARHT). ${ }^{[3]}$ The second axis of DARHT consists of a 2-kA, 20-MeV induction LINAC that uses a 3.2-MeV electron gun with a tungsten thermionicdispenser cathode. Typically the DARHT cathode current density is $10 \mathrm{~A} / \mathrm{cm}^{2}$ at $1050^{\circ} \mathrm{C}$. Under these conditions current density is space-charge limited, which is desirable since current density is independent of temperature. At lower temperature (the temperature-limited regime) there are variations in the local current density due to a nonuniform temperature profile. To obtain the desired uniform current density associated with space-charge limited operation, the coolest area on the cathode must be at a sufficiently high temperature so that the emission is space-charge limited. Consequently, the rest of the cathode is emitting at the same space-charge-limited current density but is at a higher temperature than necessary. Because cathode lifetime is such a strong function of cathode temperature, there is a severe penalty for nonuniformity in the cathode temperature. For example, a temperature increase of $50^{\circ} \mathrm{C}$ means cathode lifetime will decrease by a factor of at least four. ${ }^{[4]}$ Therefore, we are motivated to measure the temperature profiles of our large-area cathodes.

At high temperatures radiation is the dominant mechanism for heat loss. The cathodes were designed with a low-conductance mechanical support and thermal shields. We estimate that 90 percent of the heater power was radiated from the front of the cathode. Thus:

$$
\begin{aligned}
& 0.9 \mathrm{P}_{\text {heater }}=\varepsilon \sigma \mathrm{AT}^{4} \\
& \sigma=5.671 \times 10^{-12}\left[\mathrm{~W} \mathrm{~cm}^{-2} \mathrm{~K}^{-4}\right]
\end{aligned}
$$

where $\varepsilon, A$, and $T$ are the cathode emissivity, area, and temperature, and $\sigma$ is the StefanBoltzmann constant. Knowing the cathode emissivity at operating temperature is important because of its effect on required heater power. We have measured both the emissivity and temperature profiles for barium-dispenser tungsten cathodes 6.5 and 8 inches in diameter. 


\section{Experimental Setup}

We performed measurements on a facility called the Cathode Test Stand (CTS). ${ }^{[5]}$ The CTS uses a vacuum vessel 36 inches in diameter and 57 inches long. Pumping is provided by a 4000 liter/sec cryo pump and a 500 liter/sec turbo molecular pump. Because we desired both high vacuum and bakeout capability we used only metal seals. With a cold cathode the vacuum is about $3 \times 10^{-10}$ Torr after bakeout. With a hot cathode the pressure is about $5 \times 10^{-8}$ Torr. There are several viewports for viewing the cathode. We made measurements through the center port, where we could view the cathode head-on. We used a residual gas analyzer to monitor the partial pressure of various gases as we slowly heated the cathode from room temperature to about $1050^{\circ} \mathrm{C}$. The 8 inch cathode has two filament heaters embedded in the tungsten that encircle the cathode's axis; one 3.6 inches in diameter, the second 6.5 inches in diameter. Four filament leads decouple and independently power the heaters. The 6.5-inch cathode has a single filament heater 4.4-inches in diameter and two filament leads.

We measured the temperature of the cathode using a combination of multispectral-imaging pyrometry and spot pyrometry. We employed a camera and three spot pyrometers, including a hot-wire pyrometer. We photographed the cathode at operating temperature using a Photometrics STAR1 CCD camera and narrow-band interference filters at wavelengths of $0.4,0.45$, and 0.50 $\mu \mathrm{m}$. The filter bandpass was $0.04 \mu \mathrm{m}$. The filters were mounted on a stock $35 \mathrm{~mm} \mathrm{f} / 2$ camera lens. We used a stacked pair of interference filters at each wavelength to increase the blocking of out-of-band light. We converted these photos to thermal images of the cathode after calibrating the camera using a calibrated cavity blackbody. To obtain the most accurate temperatures, we operated as far as possible toward the blue end of the cathode's emission spectrum. The Planck equation $^{[6]}$ shows the reason for measuring temperature in the blue. The spectral exitance $\left(\mathrm{W} / \mathrm{cm}^{2} / \mu \mathrm{m}\right.$ emitted) of a hot surface is:

$$
\mathrm{M}(\mathrm{T}, \lambda)=\varepsilon \mathrm{C} 1\left(\mathrm{e}^{\mathrm{x}}-1\right)^{-1} \lambda^{-5}\left[\mathrm{~W} \mathrm{~cm}{ }^{-2} \mu \mathrm{m}^{-1}\right]
$$

where

$$
\begin{array}{lll}
\mathrm{T} & = & \text { temperature }\left[{ }^{\circ} \mathrm{K}\right] \\
\lambda & = & \text { wavelength }[\mu \mathrm{m}] \\
\varepsilon & = & \text { emissivity of the surface } \\
\mathrm{C} 1 & = & 3.74177 \times 10^{4}\left[\mathrm{~W} \mu \mathrm{m}^{4} \mathrm{~cm}^{-2}\right] \\
\mathrm{x} & = & \mathrm{C} 2 /(\lambda \mathrm{T}) \\
\mathrm{C} 2 & = & 14387.7\left[\mu \mathrm{m}^{\circ} \mathrm{K}\right] .
\end{array}
$$

Figure 1 is a plot of $\mathrm{M}$ for a perfect blackbody radiator $(\varepsilon=1)$ at temperatures of $900^{\circ}, 1000^{\circ}$, and $1100^{\circ} \mathrm{C}$. For a given wavelength, the fractional change in exitance when moving from one curve to another is largest on the blue end of the spectrum. One can see this more clearly from the same plot on a log scale in Figure 2. At 0.4 ? m, moving from one curve to the next changes exitance by a factor of approximately 10 . In other words, for a blackbody near $1000^{\circ} \mathrm{C}$, a measurement of exitance at 0.4 ? $\mathrm{m}$ can be off by a factor of 10 and still yield the correct temperature within $100^{\circ} \mathrm{C}$. At longer wavelengths the curves are closer together, so a 
temperature measurement is more sensitive to experimental error. A more quantitative way to display the effect is by calculating temperature contrast from the Planck equation:

$$
\Delta \mathrm{T} / \mathrm{T}=\left(\mathrm{e}^{\mathrm{x}}-1\right)\left(\mathrm{xe}^{\mathrm{x}}\right)^{-1} \Delta \mathrm{M} / \mathrm{M}
$$

Figure 3 plots the calculated change in blackbody temperature $\Delta \mathrm{T}$ necessary to cause a 10 percent change in measured exitance. For example, a 10 percent measurement of exitance at 0.4 $\mu \mathrm{m}$ would give an uncertainty in the calculated temperature of $5^{\circ} \mathrm{C}$ (using the middle curve for $1000^{\circ} \mathrm{C}$ ). A similar measurement at $4 \mu \mathrm{m}$ would give an uncertainty of more than $40^{\circ} \mathrm{C}$. Small changes in temperature cause great changes in exitance in the blue. Small changes in temperature cause small changes in exitance in the red. Measurements in the far blue yield temperatures insensitive to uncertainty in the surface emissivity. ${ }^{[7,8]}$ Measurements in the far red yield emissivity insensitive to uncertainty in the surface temperature.

In addition to acquiring thermal images with the CCD camera, we also measured the temperature at discrete points on the cathode using two Minolta-Land spot pyrometers made by a hot-wire pyrometer. The Land Model 52 has an Si detector and operates at about $1.0 \mu \mathrm{m}$, with a bandpass of $0.2 \mu \mathrm{m}$. The Land Model 241 has a Ge detector that operates from $1.1 \mu \mathrm{m}$ to $1.9 \mu \mathrm{m}$. We used a long-pass filter with the Model 241 to narrow its operating wavelength range to $1.8 \mu \mathrm{m}$, with a bandpass of about $0.3 \mu \mathrm{m}$. The Pyro Micro-Therm is a hot-wire disappearing filament spot pyrometer made by Pyrometer Instrument Co. We calibrated these three pyrometers using a cavity blackbody. The two Land pyrometers had a viewfinder for aiming at the desired spot.

(With the Model 241, we aimed the pyrometer before installing the $1.8 \mu \mathrm{m}$ filter.) The Model 52 displayed the temperature in ${ }^{\circ} \mathrm{C}$. We corrected the reading from the Model 241 to account for the effect of the filter. The hot-wire pyrometer required blending the appearance of an internal hot filament with that of the target by adjusting the current through the filament, and thus its temperature.

We calibrated the CCD camera with the filters using a calibrated cavity blackbody. We obtained a linear relationship between camera counts and integrated exitance of the blackbody at temperature T:

where

$$
\operatorname{NCS}(\mathrm{T})=\varepsilon \mathrm{KM}_{\mathrm{int}}(\mathrm{T})
$$

$$
M_{\text {int }}(T)=\int M(T, \lambda) R(\lambda) d \lambda
$$

and $R(\lambda)$ is the spectral responsivity of camera with filter.

$\mathrm{NCS}(\mathrm{T})$ is the camera counts/sec normalized to a wide open aperture setting. The sum $\mathrm{M}_{\text {int }}$ was calculated over the spectral range of the camera. $\mathrm{K}$ was a calibration constant determined for each of the three filters used. K was the same within $\pm 10 \%$ for all three filters. For calibrations, $\varepsilon$ was 0.99 for the cavity blackbody used. During the camera calibration, the linear relationship given by Eq.(4) fit the camera data to within $\pm 3 \%$, as NCS varied by two decades over the range of $900^{\circ}$ to $1100^{\circ} \mathrm{C}$. It was important to establish this linear relationship to check that the camera was calibrated properly. ${ }^{[9]}$ It indicated that systematic errors that vary with temperature were 
small. One possible source of error was leakage light due to imperfect blocking of out-of-band light in the filters. Figure 4 is a plot of NCS versus temperature calculated using Eq.(4) with

$\varepsilon=1$. We used this relationship to convert images from camera counts to temperature for a given assumed emissivity $\varepsilon$ of the cathode. For example, if the camera has 200 counts/sec, then the temperature is $1080^{\circ} \mathrm{C}$ for $\varepsilon=1$, using Figure 4 . Assuming $\varepsilon=0.65$, the temperature is about $1110^{\circ} \mathrm{C}$, corresponding to $200 / 0.65=308$ counts/sec. As previously discussed, the calculated temperature for the thermal image at 0.4 ? m did not depend strongly on the assumed value of $\varepsilon$.

\section{Experimental Data and Discussion}

Using the CCD camera, we photographed the cathodes through the center viewport of the vacuum chamber. The viewport was 0.375 -inch-thick 7056 glass, which we measured to have a transmittance of 0.93 from $0.35 \mu \mathrm{m}$ to $1.95 \mu \mathrm{m}$. The window cuts off at about $2.7 \mu \mathrm{m}$. The cathodes were about 38 inches from the camera. Figure 5 shows a thermal image of the 6.5-inch cathode taken with the 0.4 ? $\mathrm{m}$ filter. The image has been converted to temperature using Eq.(4), assuming $\varepsilon=0.65$ at $0.4 ? \mathrm{~m}$, based on the value at room temperature, as discussed below. The image is displayed in pseudocolor. Vertical and horizontal temperature profiles are plotted next to it. The profiles are taken along the image's faint vertical and horizontal lines, which pass through the coldest and hottest regions of the cathode. The temperatures in the displayed image have been quantized in $3^{\circ} \mathrm{C}$ steps, as shown by the color bar to the left. The temperatures in the profiles have not been quantized. The power to the heating element is $2728 \mathrm{~W}$, as listed near the top. The maximum temperature variation in the image is about $26^{\circ} \mathrm{C}$, a variation that is not sensitive to the assumed value of $\varepsilon$ at $0.4 ? \mathrm{~m}$.

Figure 6 shows a thermal image of the 8 -inch cathode taken with the $0.4 ? \mathrm{~m}$ filter. The power to the two heating elements is listed near the top. The maximum temperature variation is about $38^{\circ} \mathrm{C}$ for this ratio of heating power to the elements $(1.8: 1)$.

Figure 7 shows an image taken with a ratio of heating power to the elements of 4.1:1. The shape of the temperature profiles has changed. The cathode is cooler in the center since most of the heater power goes to the outer filament. The maximum temperature variation is about the same as in Figure 6. We tried four different ratios of heating power, from 1.2 to 4.1. We could change the shape of the temperature profiles but could not decrease the maximum temperature variation. The observed temperature variations were not radially symmetric, which we attributed in part to the azimuthal gap in the heaters where the heater leads extended from the back of the cathode. The coolest regions in the thermal images for both cathodes were on the edge at a point nearest this gap. The gaps were at the bottom right and upper left of the 8-inch and 6.5-inch cathodes respectively.

Three effects combined to slightly change the measured temperature distribution for the cathodes. First, rays from the edge of the cathode were incident on the 0.4 ? m filter at a finite angle with respect to the axis. This gave the filter an effective tilt for rays from the cathode edge. Second, there was $\cos ^{n}(\theta)$ lens rolloff. ${ }^{[10]}$ Finally, a small amount of multiple scattering existed between flat surfaces in the stacked filters. To minimize the multiple scattering we mounted the stacked filters on the lens so that the primary filter nearest the source had a bandpass of $0.04 \mu \mathrm{m}$ 
and was tilted at $1^{\circ}$. The second filter had a bandpass of $0.08 \mu \mathrm{m}$ and was not tilted. The filters' dull sides faced each other.

We measured the three combined effects by positioning a cavity blackbody at $1050^{\circ} \mathrm{C}$ at various locations in front of the camera. The resulting correction applied to the thermal images was zero at the image center and increased as the square of the distance from the image center. The correction was radially symmetric. With the cathode in the image center, the correction was zero at the cathode center and $+2^{\circ} \mathrm{C}$ and $+3^{\circ} \mathrm{C}$ at the edge of the 6.5 -inch and 8-inch cathodes respectively. Thermal images for the 6.5 -inch cathode were averages of two images taken with the filter pair rotated by $0^{\circ}$ and $180^{\circ}$. Images for the 8 -inch cathode were taken with a single orientation of the filters.

One can judge the accuracy of the corrections discussed above by comparing images taken with the camera pointed at the center with those taken at the top edge of the cathode. Figure 8 shows an image with the camera aimed at the top edge of the 6.5-inch cathode. We took Figure 9 with the camera aimed at the center. We applied the above correction to both images. In both cases we took the vertical line profiles through the cathode center (Figure 9 is the same as Figure 5 but with the line profiles through the cathode center). The temperatures of the vertical line profiles from cathode center to top edge agreed within $2^{\circ} \mathrm{C}$ in Figures 8 and 9. A similar comparison for the 8-inch cathode demonstrated that the profiles from center to bottom edge agreed within $4^{\circ} \mathrm{C}$. These comparisons also showed that any effects from vignetting were small.

We also measured temperature profiles for the 6.5-inch cathode using the Land 52 and hot-wire spot pyrometers. Figure 10 shows the temperature variations on a horizontal profile through the center of the cathode. We plotted the maximum temperature difference between the center and that at any other point on the profile. All temperatures plotted in Figure 10 were measured assuming $\varepsilon=1$, commonly called the "brightness temperature." Figure 11 shows similar results for a vertical profile through the center. The measured variations from the center agreed within $\pm 3^{\circ} \mathrm{C}$ for the two pyrometers. The variations from the center for the thermal image agreed with that from the pyrometers within about $\pm 8^{\circ} \mathrm{C}$ at each point along the profiles. From Figures 10 and 11, the maximum temperature variation (largest change in temperature from any point to any other point) for the 6.5 -inch cathode were $26^{\circ}, 21^{\circ}$, and $24^{\circ} \mathrm{C}$ from the thermal image, Land 52 and hot-wire pyrometers respectively. Thus the three instruments measured the same maximum temperature variation within $5^{\circ} \mathrm{C}$. The spot pyrometers slightly underestimated the temperature variations since they averaged over a finite spot size. Also, the spots had to be at least half a spot diameter in from the cathode edge.

We estimate the uncertainties in the temperature variation along the temperature profiles for the thermal images are $\pm 5^{\circ} \mathrm{C}$ and $\pm 8^{\circ} \mathrm{C}$ for the 6.5 -inch and 8-inch cathodes respectively.

Images were normally acquired with the camera and chamber window enclosed in a dark box to prevent stray ambient light from scattering into the camera. The other four viewports on the chamber were also covered. To determine the effect of a light leak, we intentionally introduced the greatest possible stray light by removing the dark box and uncovering the other four viewport windows. The resulting light was easily visible in the image and raised the apparent temperature of the cathode by about $10^{\circ} \mathrm{C}$. This indicated with the box in place that such stray light was 
negligible. We also turned off the residual gas analyzer and vacuum ion gauge during the measurements because they were possible sources of stray light.

To determine uncertainty in absolute temperature, we analyzed measurements made at a single point at the center of the 6.5-inch cathode. It was convenient to think of the data as coming from five channels at different wavelengths. We plotted the data as a temperature field ${ }^{[9]}$ as shown in Figure 12. The temperature field is a plot of temperature calculated from the measured exitance for each channel. We calculated the temperature for each assumed value of emissivity. We plotted the five channels on the $\mathrm{x}$ axis with the calculated temperatures on the $\mathrm{y}$ axis. The first three channels were the CCD camera with the three different filters. Channel \#4 was the Model 52 spot pyrometer. Channel \#5 was the Model 241 spot pyrometer with a narrow-band filter.

Since we expected the most accurate temperatures to come from the bluest channel, we used Channel \#1 to find the temperature bounds. The hollow circle plotted for Channel \#1 is the temperature if $\varepsilon=0.3$. We draw a horizontal dotted line for a temperature of $1155^{\circ} \mathrm{C}$ corresponding to $\varepsilon=0.30$. The solid dot for Channel \#1 was at the temperature of $1087^{\circ} \mathrm{C}$ if $\varepsilon=$ 1. We drew another dotted line through this point. Since $\varepsilon \leq 1$, the dotted lines are the absolute bounds on the actual temperature (assuming that $\varepsilon \geq 0.30$ ). These bounds apply to all channels, since the actual temperature is the same for each. These bounds imply that $\varepsilon$ is between 0.39 and 0.52 for Channel \#5 at $1.8 \mu \mathrm{m}$. Also, $\varepsilon$ is between 0.39 and 0.62 at $1.0 \mu \mathrm{m}$ for Channel \#4. Note that we have constrained the value of $\varepsilon$ at $1.8 \mu \mathrm{m}$ to be $0.45 \pm 0.07$ using conservative bounds of 0.30 and 1.0 for $\varepsilon$ at $0.4 ? \mathrm{~m}$.

We measured emissivity at room temperature using a 1-inch-diameter sample of the cathode material obtained from the manufacturer. ${ }^{[1]}$ The curve in Figure 13 shows the results. Assuming that $\varepsilon$ does not change from its value of 0.65 at $0.4 ? \mathrm{~m}$ at room temperature, the actual temperature at the center of the 6.5 -inch cathode is $1111^{\circ} \mathrm{C}$, indicated by the solid horizontal line in Figure 12. The temperature bounds are $+44^{\circ} \mathrm{C},-24^{\circ} \mathrm{C}$.

The brightness temperature $(\varepsilon=1)$ at the center of the 6.5 -inch cathode was measured to be $1087^{\circ}, 1068^{\circ}$, and $1032^{\circ} \mathrm{C}$, by the camera, hot-wire pyrometer, and Land 52 pyrometer respectively. These measurements were taken at wavelengths of $0.4 ? \mathrm{~m}, 0.6 \mu \mathrm{m}$, and $1.0 \mu \mathrm{m}$ respectively.

Figure 13 summarizes the emissivity results for the 6.5 -inch cathode. The emissivities at $1.0 \mu \mathrm{m}$ and $1.8 \mu \mathrm{m}$ come from Channels 4 and 5 of the temperature field in Figure 12. The solid triangle at $2.2 \mu \mathrm{m}$ (peak wavelength for blackbody emission at $1050^{\circ} \mathrm{C}$ ) is the average emissivity of the cathode calculated using Eq.(1). It is the emissivity averaged over the cathode surface and over all emission wavelengths. The result was $\varepsilon_{\text {ave }}=0.56$, assuming that 90 percent of the power was radiated from the front of the cathode. The error bars in Figure 13 derive from the temperature bounds discussed above.

The emissivities at $1.8 \mu \mathrm{m}$ and $2.2 \mu \mathrm{m}$ are higher than that measured at room temperature for the 1-inch cathode sample, suggesting that emissivity beyond about $1.8 \mu \mathrm{m}$ rises as the cathode heats 
from room temperature. We obtained the values of $\varepsilon$ for the 8 -inch cathode at $1.0 \mu \mathrm{m}$ and $2.2 \mu \mathrm{m}$ by a similar analysis. They were lower than that of the 6.5 -inch cathode by about 0.04 .

Displaying the data as the temperature field in Figure 12 shows graphically how bounds on emissivity in the blue at 0.4 ? m constrain the temperature. It also shows how temperature determined in the blue then constrains the emissivity in the red. The Channels at $0.45 \mu \mathrm{m}$ and 0.5 $\mu \mathrm{m}$ provided a consistency check.

\section{Summary and Conclusions}

We used multispectral imaging pyrometry to measure absolute temperature and maximum temperature variation of the 6.5-inch and 8-inch cathodes.

The maximum temperature variation was $38 \pm 8^{\circ} \mathrm{C}$ for the 8 -inch cathode and $26 \pm 5^{\circ} \mathrm{C}$ for the 6.5 -inch cathode. The thermal images showed a cool region near the gap in the heater elements for both cathodes. We did not meet the design temperature uniformity goal of a variation of $10^{\circ} \mathrm{C}$ for the cathodes.

The brightness temperature $(\varepsilon=1)$ at the center of the 6.5 -inch cathode was $1068^{\circ} \mathrm{C}$ (near 0.6 $\mu \mathrm{m}$ ) using a hot-wire spot pyrometer. The heater power was $2.73 \mathrm{~kW}$. The thermal image (at 0.4 $\mu \mathrm{m})$ gave about a $20^{\circ} \mathrm{C}$ hotter brightness temperature.

We measured the absolute temperature in Kelvin at the center of both cathodes with an uncertainty of $\pm 3 \%$ using conservative bounds of 0.3 and 1 for the emissivity at $0.4 ? \mathrm{~m}$. The absolute temperatures at the center were $1384^{\circ} \mathrm{K}\left(1111^{\circ} \mathrm{C}\right)$ and $1342^{\circ} \mathrm{K}\left(1072^{\circ} \mathrm{C}\right)$ for the 6.5 -inch and 8 -inch cathodes, with heater power of $2.73 \mathrm{~kW}$ and $3.18 \mathrm{~kW}$ respectively.

Using these absolute temperatures, we determined the average emissivity at operating temperature using the $\mathrm{T}^{4}$ radiation law and the heater power. The average emissivity was 0.52 \pm 0.07 for the 8 -inch cathode and $0.56 \pm 0.07$ for the 6.5 -inch cathode, assuming that 90 percent of the heater power was radiated from the front of the cathode.

We obtained a linear relationship between camera counts and integrated exitance of a reference cavity blackbody, indicating that the camera was calibrated correctly. 


\section{References}

1. S. Humphries Jr., Charged Particle Beams (New York: John Wiley \& Sons, 1990), 283.

2. W. C. Turner, Y. J. Chen, W. E. Nexsen, M. C. Green, G. Miram \& A. V. Nordquist, "Highbrightness high-current density cathode for induction LINAC FELs," in Proceedings of the 1988 LINAC Conference (Newport News, Va.): 341.

3. M. J. Burns, B. E. Carlsten, T. J. Kwan, D. C. Moir, D. S. Prono, S. A. Watson, E. L. Burgess, H. L. Rutkowski, G. J. Caporaso, Y. J. Chen, Y. J. (Judy) Chen, S. Sampayan, \& G. Westenkow, "DARHT accelerators update and plan for initial operations," in Proceedings of the IEEE Particle Accelerators Conference (New York, 1999): 617.

4. J. L. Cronin, "Modern dispenser cathodes," IEEE Proceedings 128, no. 1 (1981): 19.

5. C. Fortgang, C. Hudson, D. Macy, M. Monroe, K. Moy, D. Prono, "The cathode test stand for the DARHT second-axis," in Proceedings of the $19^{\text {th }}$ International LINAC Conference (Chicago, Ill.), (1998): 171.

6. J. Vincent, Fundamentals of Infrared Detector Operation and Testing (New York: John Wiley \& Sons, 1990), 102.

7. E. Blanco, J. Mexmain, \& P. Chapron, “Temperature measurements of shock heated materials using multispectral pyrometry: Application to bismuth," Shock Waves 9 (1999): 209.

8. P. Herve, P. Masclet, A. Lefevre, \& I. Gobin, "Ultra-violet Pyrometry" (paper presented at the $4^{\text {th }}$ Symposium on Temperature and Thermal Measurement in Industry and Science, Helsinki, Finland, September 1990), 315.

9. D. B. Holtkamp, "A robust method for obtaining temperatures with multispectral pyrometry: Application to bismuth," LANL P-22 white paper (internal publication).

10. M. Bass (ed.), Handbook of Optics (New York: McGraw-Hill, 1995), 1.88.

11. Heat Wave, Inc., \#831-722-9081, type 61282 M coated, p/n sk0616699, lot \# 99-1369-1.

\section{DISCLAIMER}

This report was prepared as an account of work sponsored by an agency of the United States Government. Neither the United States Government nor any agency thereof, nor any of their employees, nor any of their contractors, subcontractors or their employees, makes any warranty, express or implied, or assumes any legal liability or responsibility for the accuracy, completeness, or any third party's use or the results of such use of any information, apparatus, product, or process disclosed, or represents that its use would not infringe privately owned rights. Reference herein to any specific commercial product, process, or service by trade name, trademark, manufacturer, or otherwise, does not necessarily constitute or imply its endorsement, recommendation, or favoring by the United States Government or any agency thereof or its contractors or subcontractors. The views and opinions of authors expressed herein do not necessarily state or reflect those of the United States Government or any agency thereof.

\section{DISTRIBUTION LIST}

U.S. Department of Energy

National Nuclear Security

Administration

Nevada Operations Office

Technical Information Resource Center

P.O. Box 98518

Las Vegas, NV 89193-8518
U.S. Department of Energy

Office of Scientific and Technical

Information

P.O. Box 62

Oak Ridge, TN 37831
U.S. Department of Energy

National Nuclear Security

Administration

Nevada Operations Office

Reading Facility

P.O. Box 98521

Las Vegas, NV 89193-8518 
Figure 1

Planck Radiation Law for Blackbody Exitance $\left(W / \mathrm{cm}^{2} / \mu \mathrm{m}\right)$

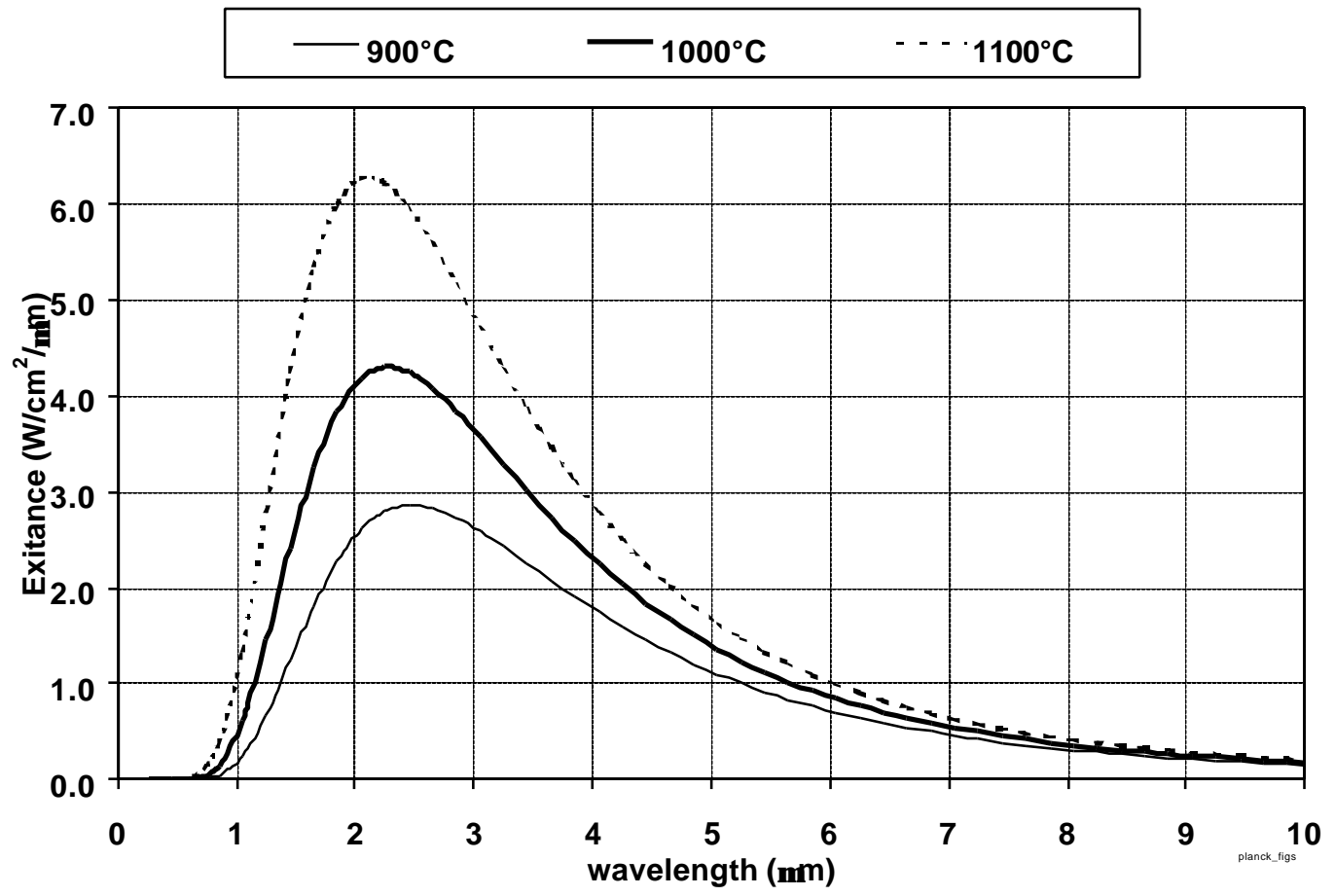

Figure 2

Planck Radiation Law for Blackbody Exitance $\left(W / \mathrm{cm}^{2} / \mu \mathrm{m}\right)$

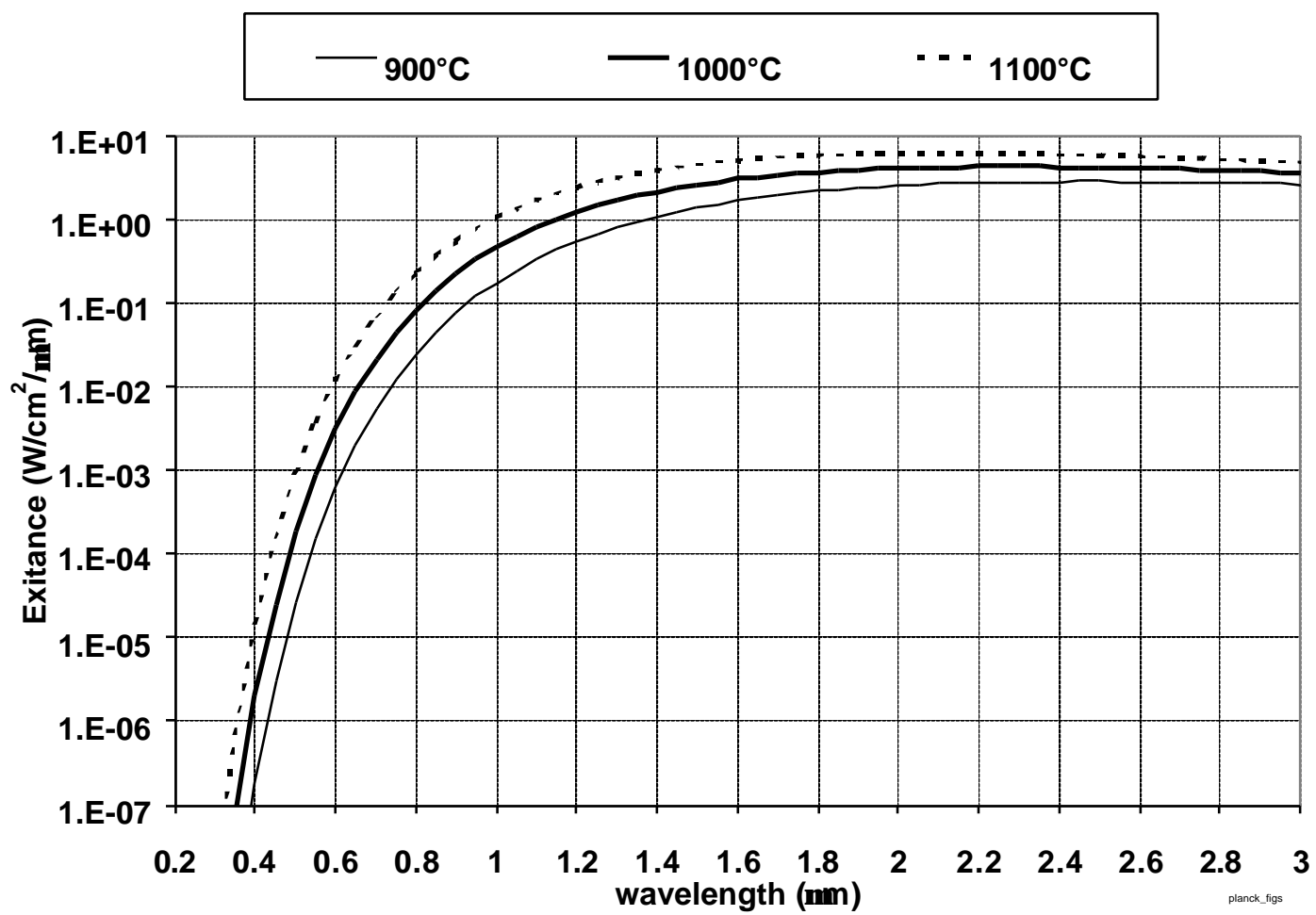


Figure 3

Change in Temperature for $10 \%$ Change in Blackbody Exitance

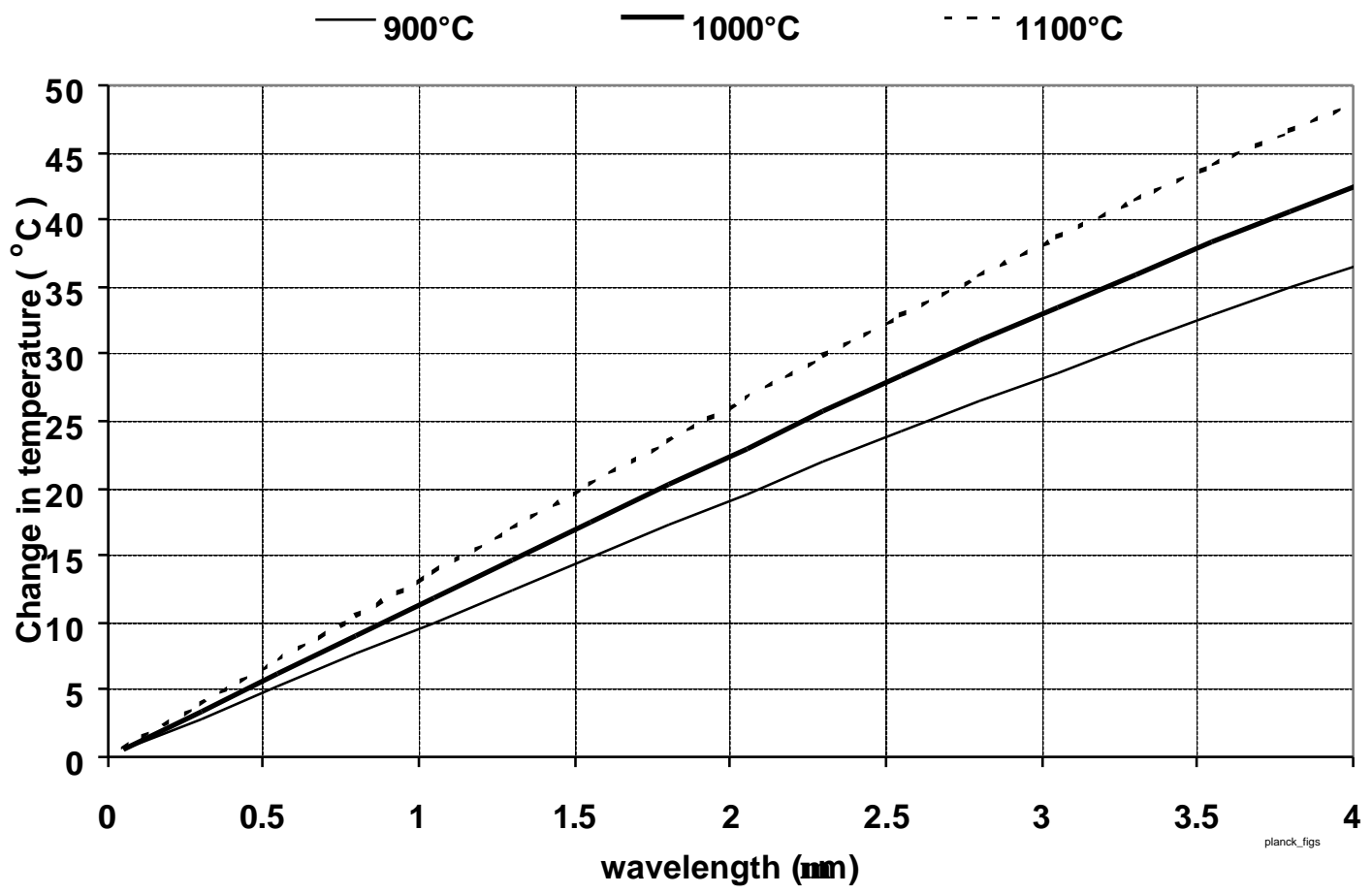

Figure 4

Normalized Camera Counts/Sec with $0.4-\mu \mathrm{m}$ Filter for $\varepsilon=1$

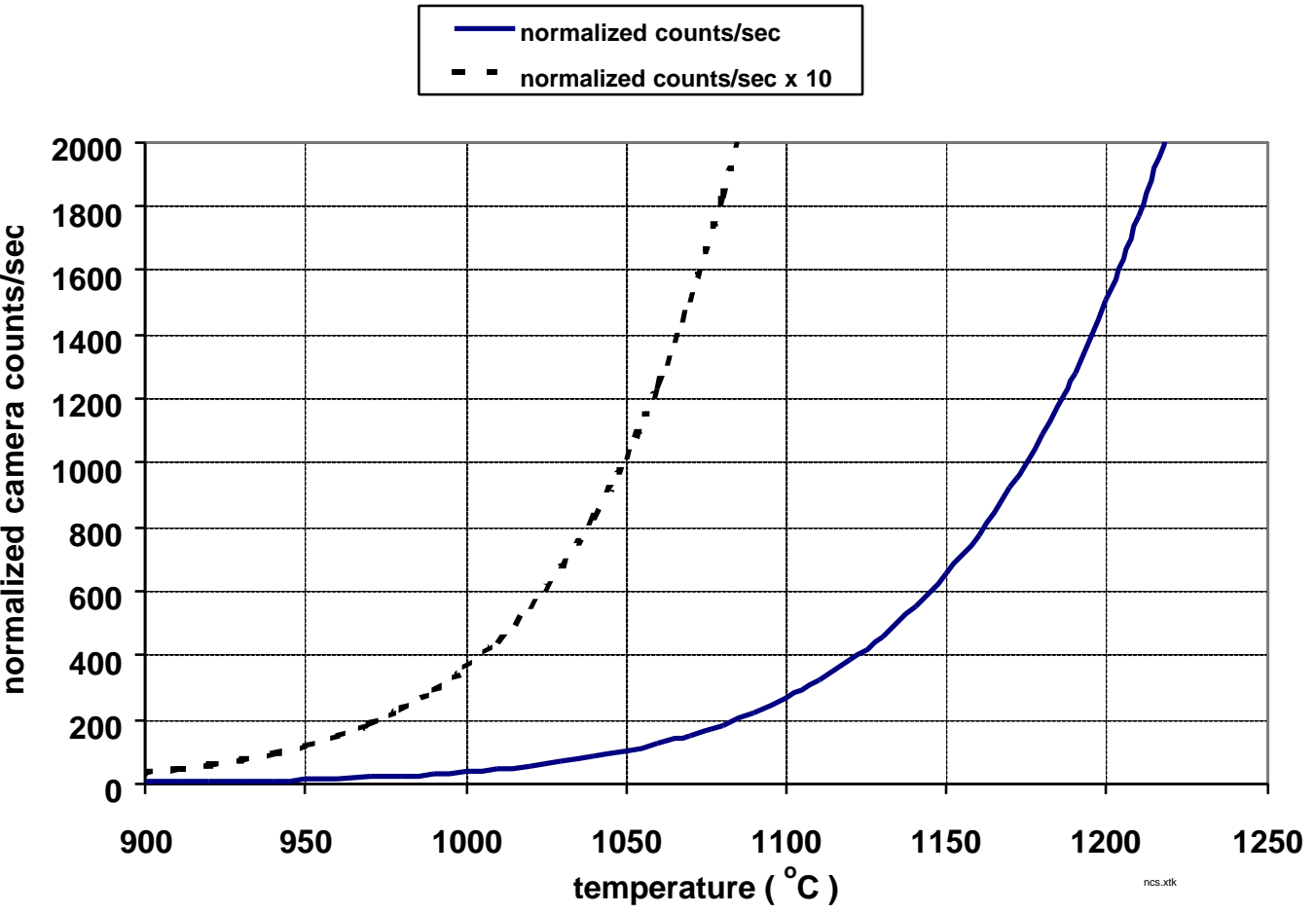


Figure 5

Thermal Image of 6.5-Inch Cathode with $0.4-\mu \mathrm{m}$ Filter $\left({ }^{\circ} \mathrm{C}\right.$ for $\left.\varepsilon=0.65\right)$

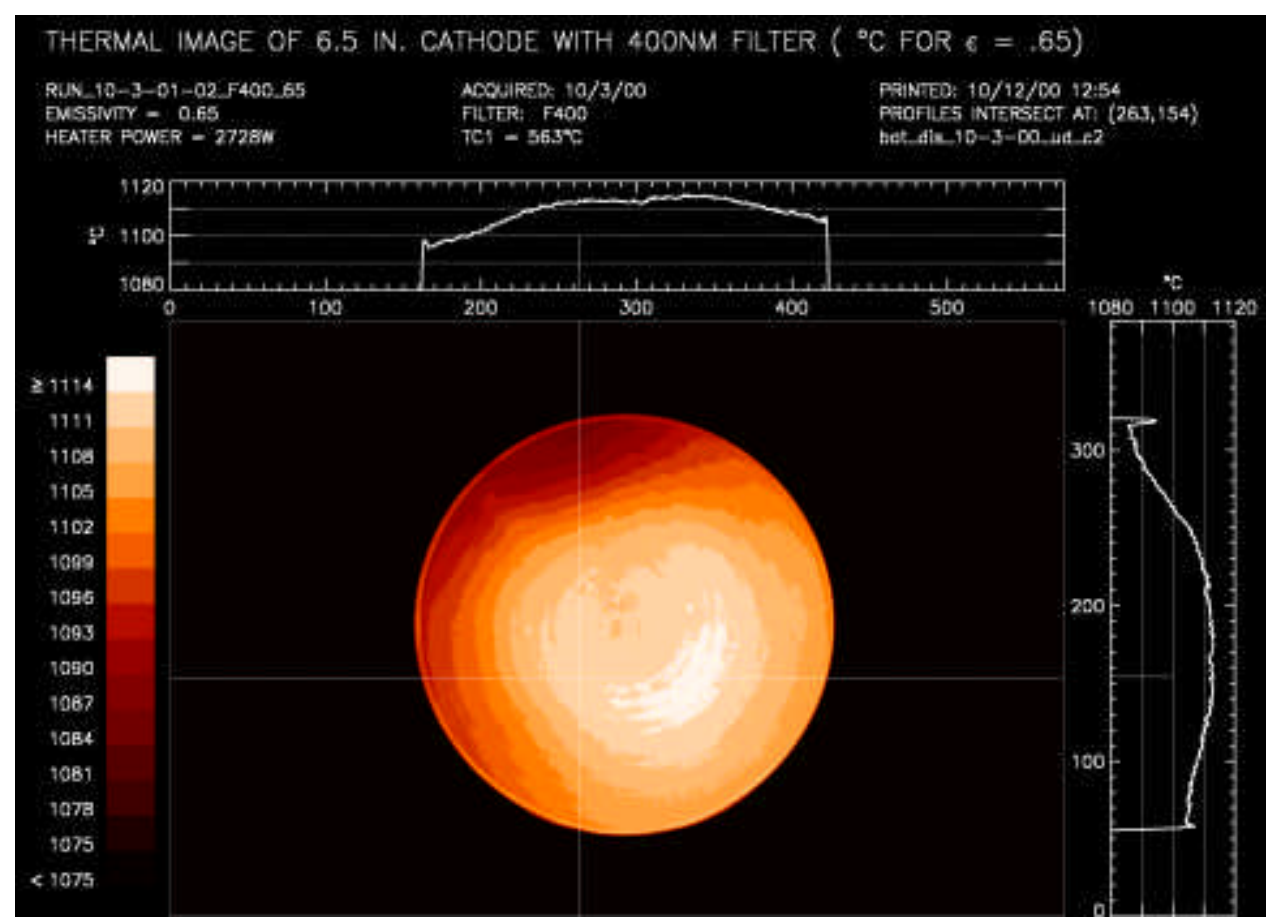

Figure 6

Thermal Image of 8-Inch Cathode with $0.4-\mu \mathrm{m}$ Filter $\left({ }^{\circ} \mathrm{C}\right.$ for $\varepsilon=0.65$ )

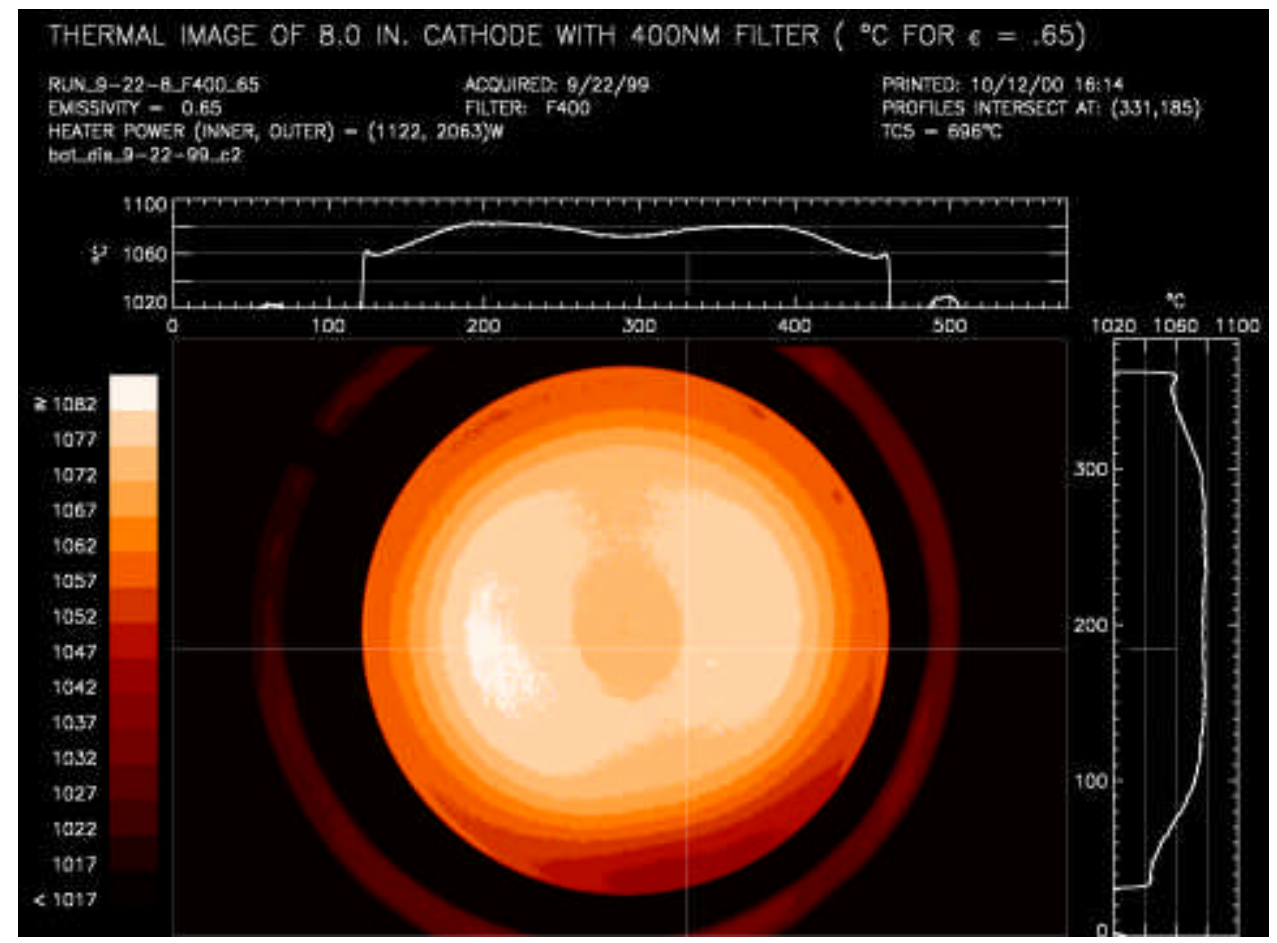


Figure 7

Thermal Image of 8-Inch Cathode with

0.4- $\mu \mathrm{m}$ Filter $\left({ }^{\circ} \mathrm{C}\right.$ for $\left.\varepsilon=\mathbf{0 . 6 5}\right)$

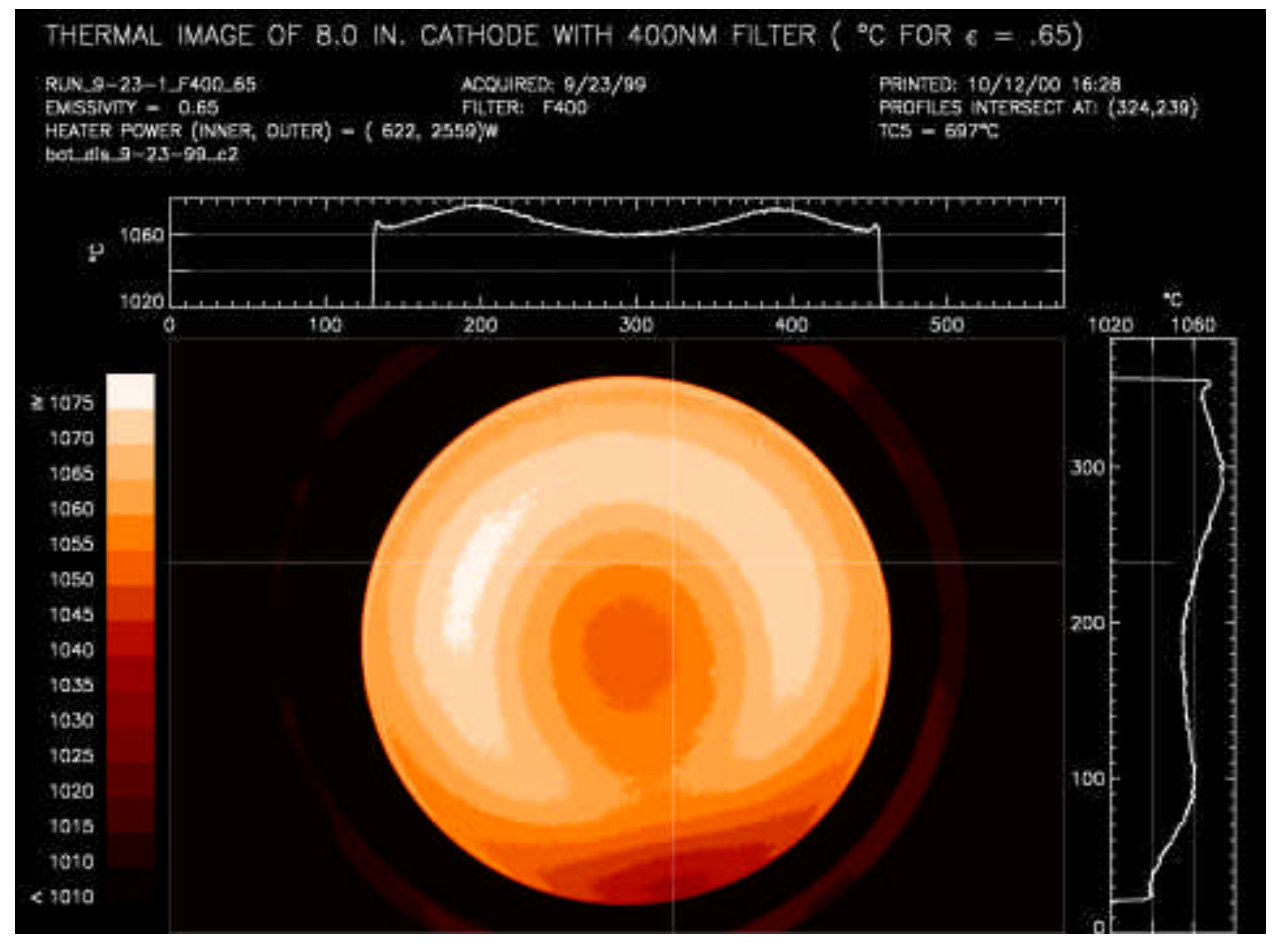

Figure 8

Thermal Image of 6.5-inch Cathode with 0.4- $\mu$ m Filter (Camera Aimed at Top Edge)

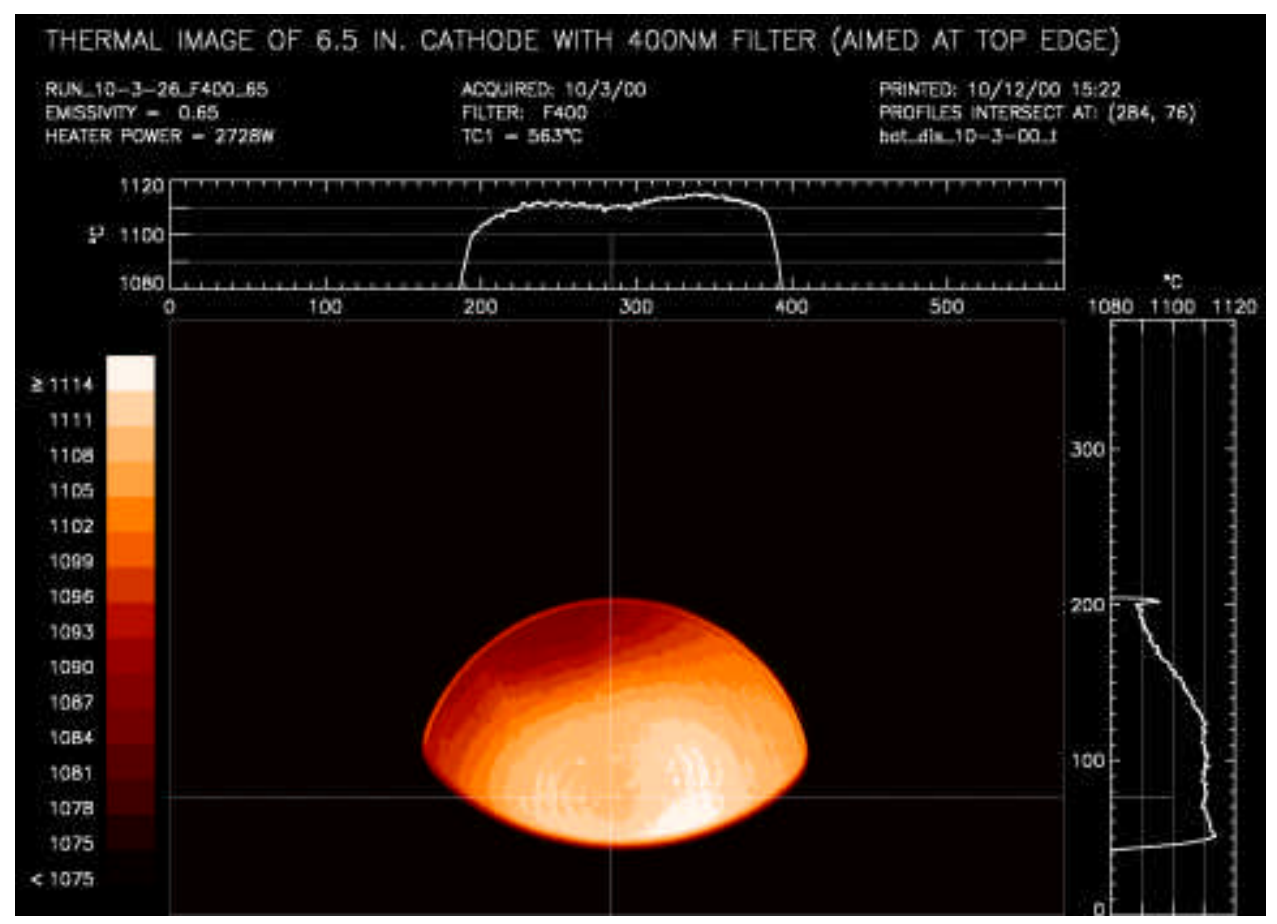


Figure 9

Thermal Image of 6.5-Inch Cathode with 0.4- $\mu \mathrm{m}$ Filter

(Camera Aimed at Center)

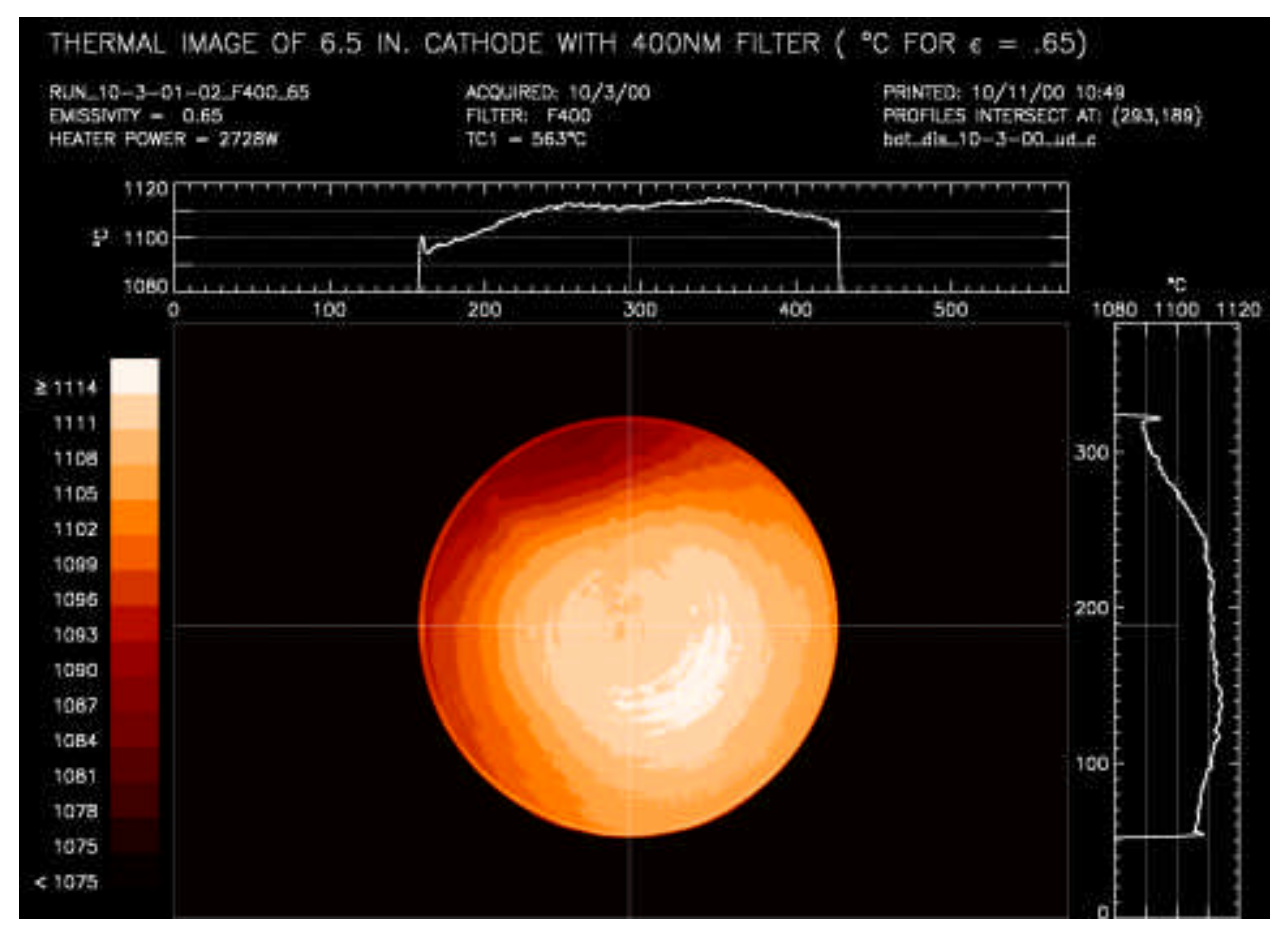

Figure 10

Temperature variations of 6.5 -inch cathode with respect to center on horizontal profile through center for $\varepsilon=1$

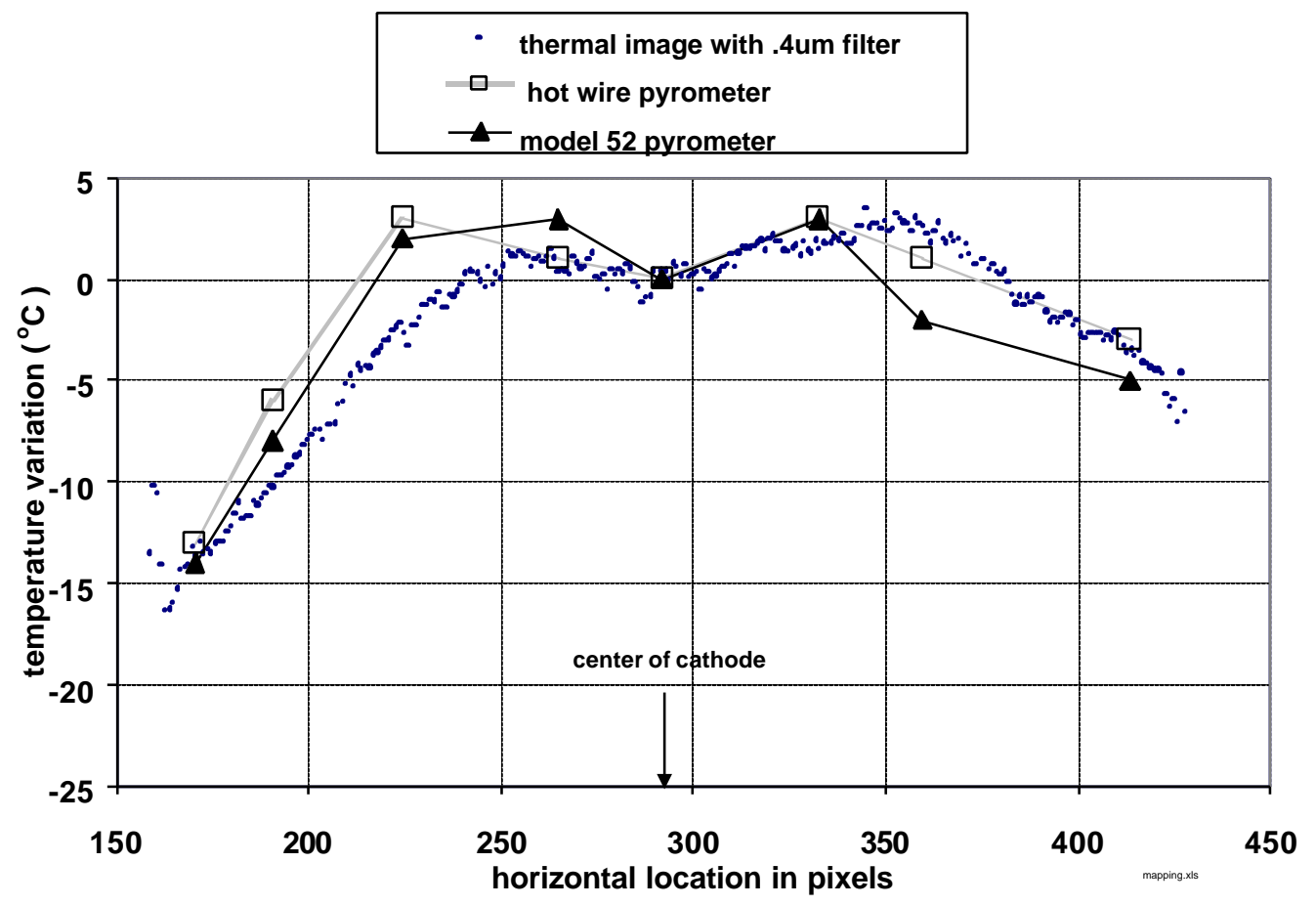


Figure 11

Temperature Variations of 6.5-Inch Cathode with Respect to Center on Vertical Profile Through Center for $\varepsilon=1$

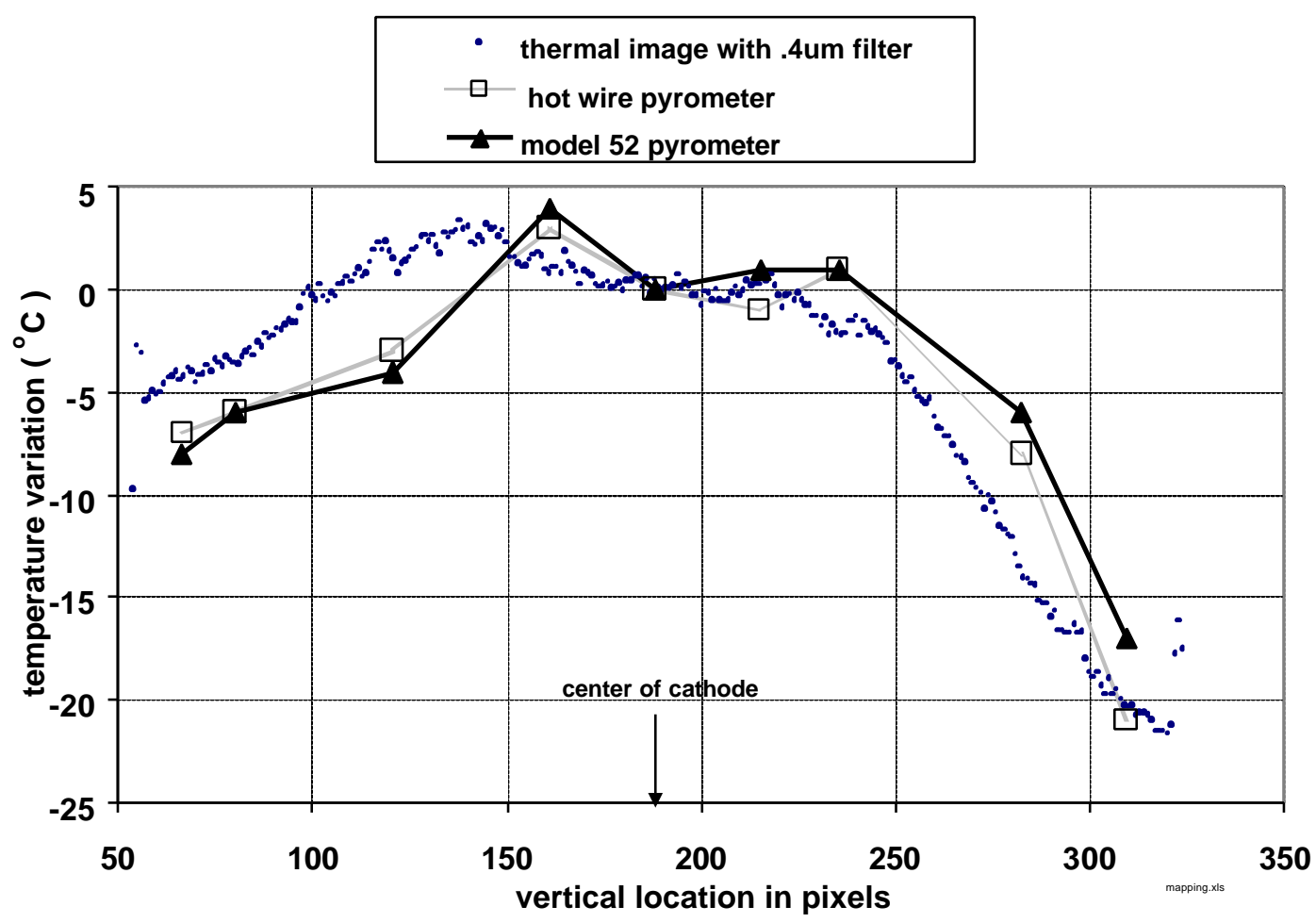


Figure 12

Temperature Field at Center of 6.5-Inch Cathode

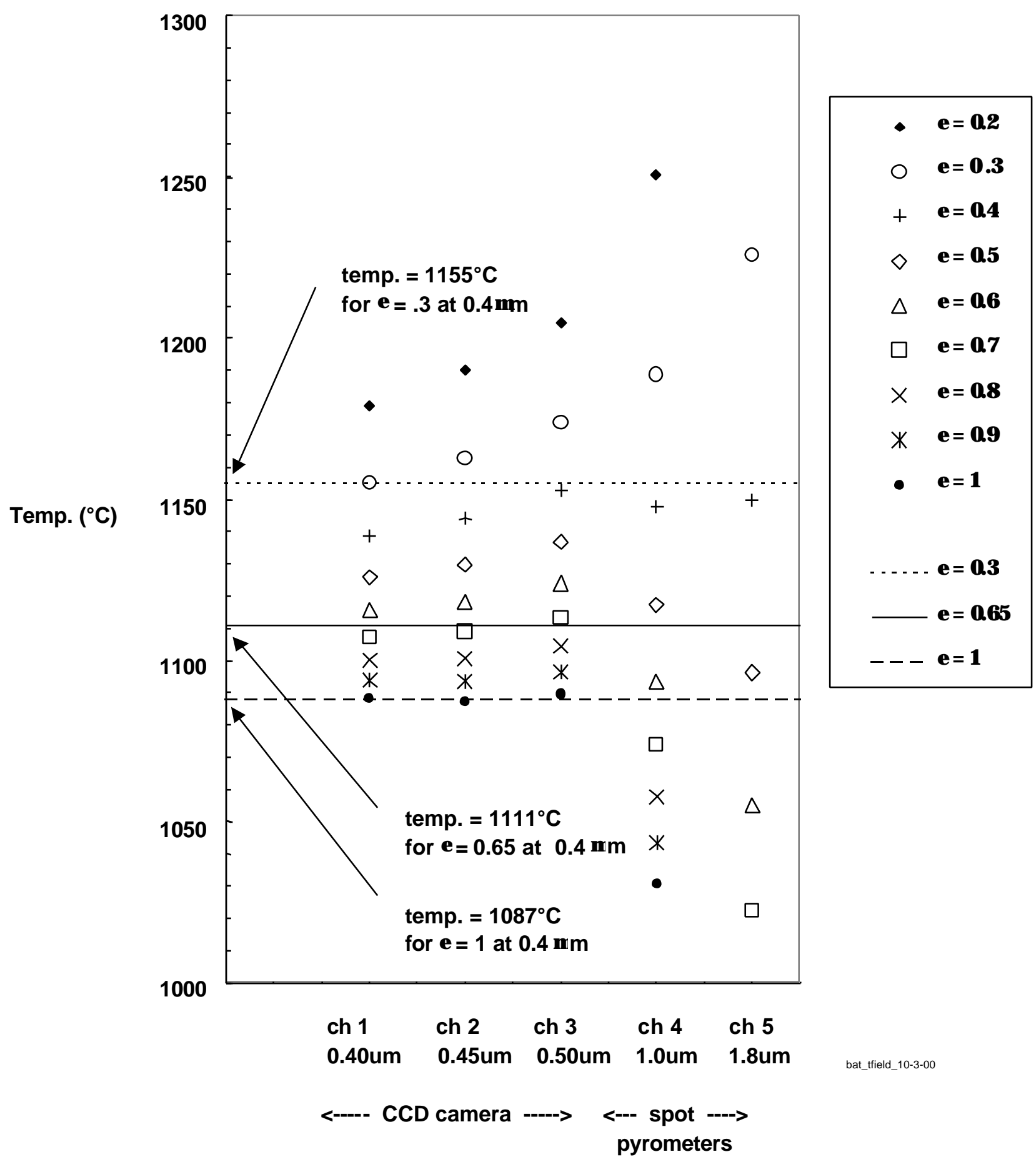


Figure 13

Summary of Emissivity at the Center of the 6.5-Inch Cathode

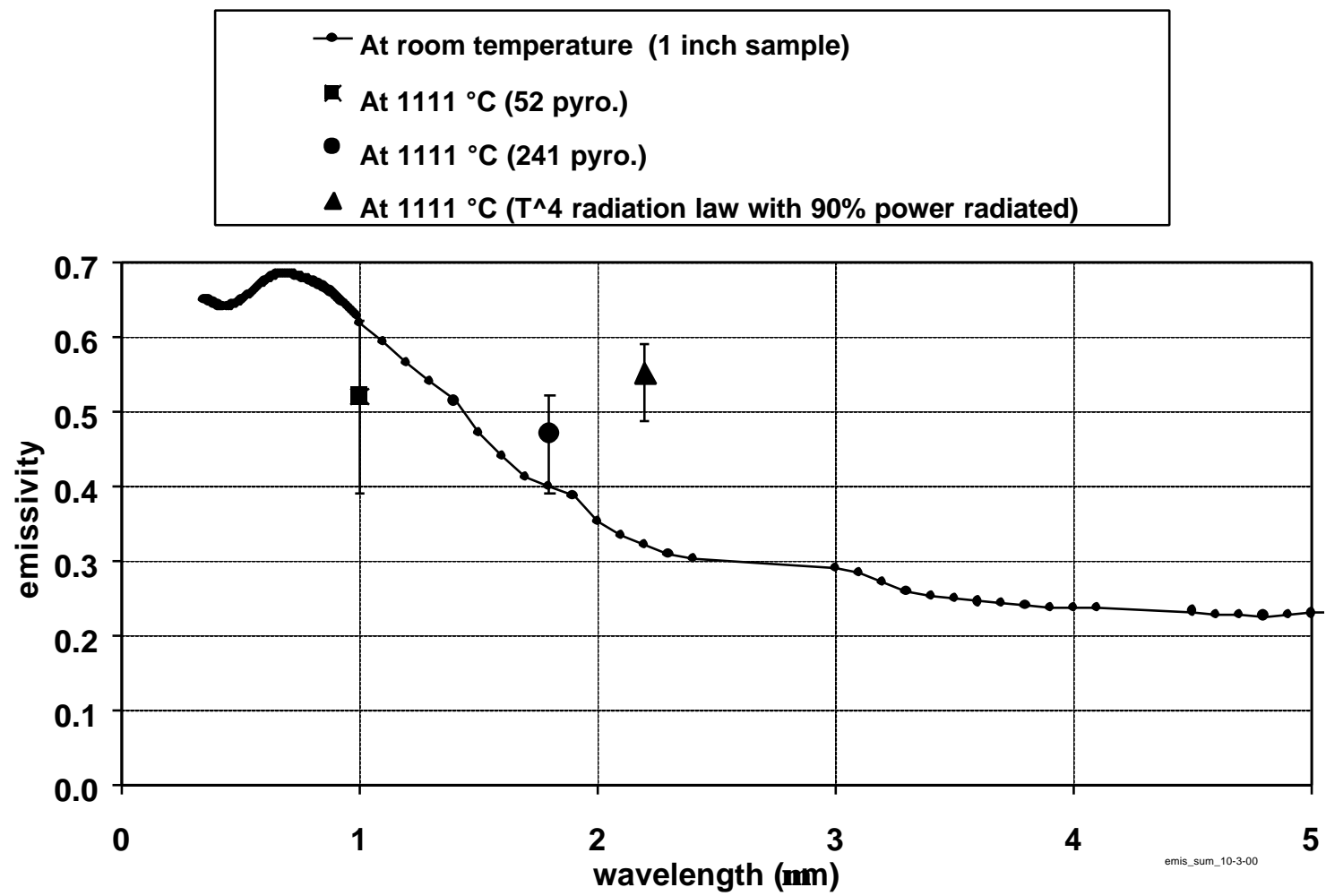

